\title{
Atmospheric particle size and composition measurements to support light extinction calculations over the Indian Ocean
}

\author{
Zohir Chowdhury, ${ }^{1}$ Lara S. Hughes, and Lynn G. Salmon \\ Environmental Engineering Science Department, California Institute of Technology, Pasadena, California \\ Glen R. Cass \\ School of Earth and Atmospheric Sciences, Georgia Institute of Technology, Atlanta, Georgia
}

\begin{abstract}
The size distribution and chemical composition of the atmospheric aerosol at the Kaashidhoo Climate Observatory (KCO) in the Republic of Maldives was determined during the winter northeast monsoon season to aid in determining the light scattering and light absorption properties of the aerosol particles in that region. These experiments were conducted over 8 two-day periods during February 11-26, 1999, using filter-based samplers and cascade impactors operated at ambient relative humidity which was in the range of $80-89 \%$ relative humidity over $83 \%$ of the period sampled. Fine particle concentrations $\left(D_{a}<1.8 \mu \mathrm{m}\right)$ averaged $17.7( \pm 0.22) \mu \mathrm{g} \mathrm{m}^{-3}$ and varied between $8.4( \pm 0.33)-24.7( \pm 0.21) \mu \mathrm{g} \mathrm{m}^{-3}$ over the period studied. Sulfate ion and carbonaceous aerosols are the largest contributors to the fine particle mass concentration, accounting for $33-37 \%$ and $26-27 \%$ of the fine mass, respectively. Calcium carbonate contributes $3 \%$ of the mass measured on the impactor stages. Ammonium, nitrate, and chloride ion account for $7-9,1$, and $0-1 \%$ of the fine particle mass, respectively. The residual mass of as yet undetermined fine particle material stands at $28-30 \%$. Black elemental carbon particles contribute $6-11 \%$ of the fine particle mass concentration and dominate light absorption in the atmosphere at KCO (A. Eldering et al., unpublished manuscript, 2001). These fine particle concentrations are comparable to those found in major cities in the United States and are surprisingly high for a remote location such as the Maldive Islands, which is located downwind of the Indian subcontinent.
\end{abstract}

\section{Introduction}

Increased airborne particle concentrations due to human activities have the potential to increase both light scattering and light absorption in the atmosphere. Light scattering and light absorption by atmospheric particles over broad regions of the Earth, such as the Indian Ocean, can affect regional climatic conditions by altering the distribution of solar radiation and hence atmospheric and surface temperature. This is particularly true in the vicinity of the Indian subcontinent where 40-hour average fine particle concentrations (aerodynamic diameter $D_{a}<$ $2.1 \mu \mathrm{m})$ in the atmosphere of the city of Mumbai have been measured at levels as high as $113 \mu \mathrm{g} \mathrm{m}^{-3}$ (S. K. Varghese et al., Aerosol and inorganic ion size distributions at Mumbai, India, during the INDOEX-IFP (1999), manuscript in preparation, 2001). Even after substantial dilution, fine particle concentrations of more than $15.8 \mathrm{\mu g} \mathrm{m}^{-3}$ have been reported in the regional plume advected over the Indian Ocean during the northeast monsoon [Krishnamurti et al., 1998].

\footnotetext{
T Now at School of Earth and Atmospheric Sciences, Georgia Institute of Technology, Atlanta, Georgia.
}

Copyright 2001 by the American Geophysical Union.

Paper number 2000JD900829.

0148-0227/01/2000JD900829\$09.00.
The earliest investigations of the potential for climate forcing by airborne particles focused on light scattering by sulfate aerosols. These studies showed that in clear-sky conditions the scattering of light back into space by atmospheric particles cools the planet [Charlson et al., 1990, 1991, 1992; Wigley, 1989; Kiehl and Briegleb, 1993; Taylor and Penner, 1994]. In contrast, if atmospheric particles in the polluted layer near the ocean's surface absorb a significant amount of light, the conversion of that energy into heat could raise the temperature of the lower atmosphere and at the same time affect the ocean surface temperature, thereby altering climate through changes in water vapor fluxes [Kiehl, 1994].

Common aerosol components like sulfate and nitrate scatter light but produce negligible light absorption [Larson et al., 1989; Zhang et al., 1993; Eldering et al., 1994]. In contrast, most of the light absorption in the atmosphere is thought to arise from light absorption by particle-phase black elemental carbon [Andreae, 1995], with generally smaller contributions from some types of suspended soil dust [Prospero, 1979]. In order to calculate the light absorption by a particular mixture of aerosol particles it is necessary to know the concentration, composition, and size distribution of the airborne particles, especially the black elemental carbon content of the aerosol. Yet, at present, there are no data that describe in detail how the various aerosol chemical components, and especially black carbon, are distributed as a function of size over the Indian Ocean.

The purpose of the present paper is to describe a series of experiments in which the size distributions and concentrations of 
Caltech Filter Sampler
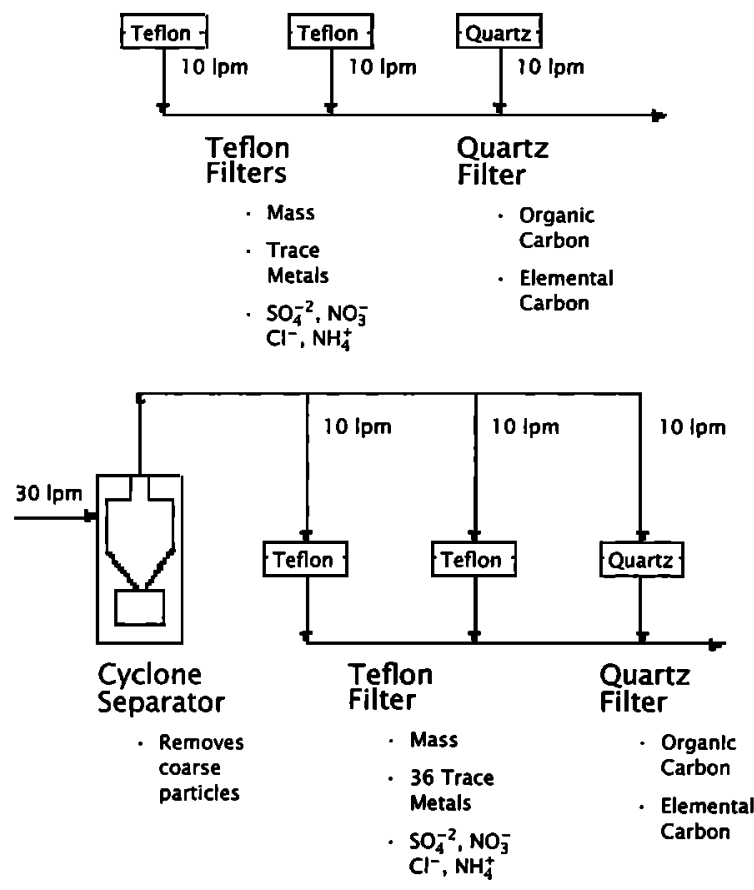

MOUDI Impactors
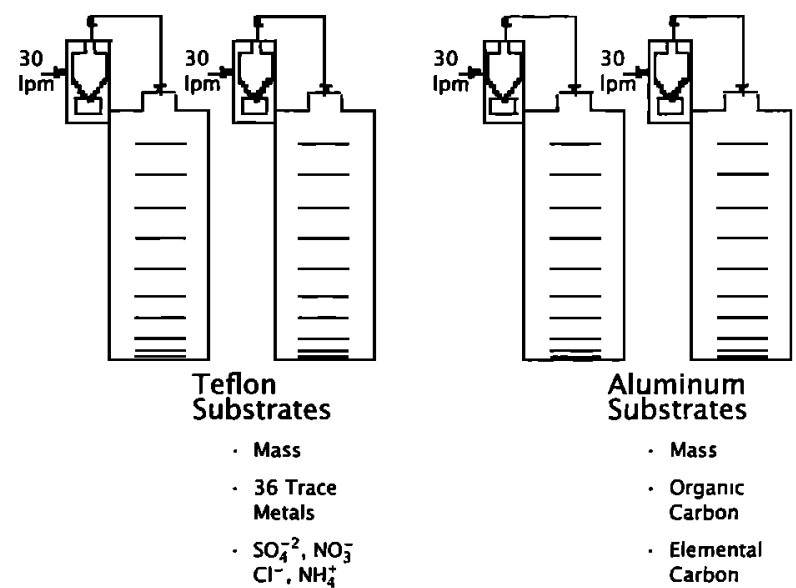

Graseby-Anderson Speciation Sampler

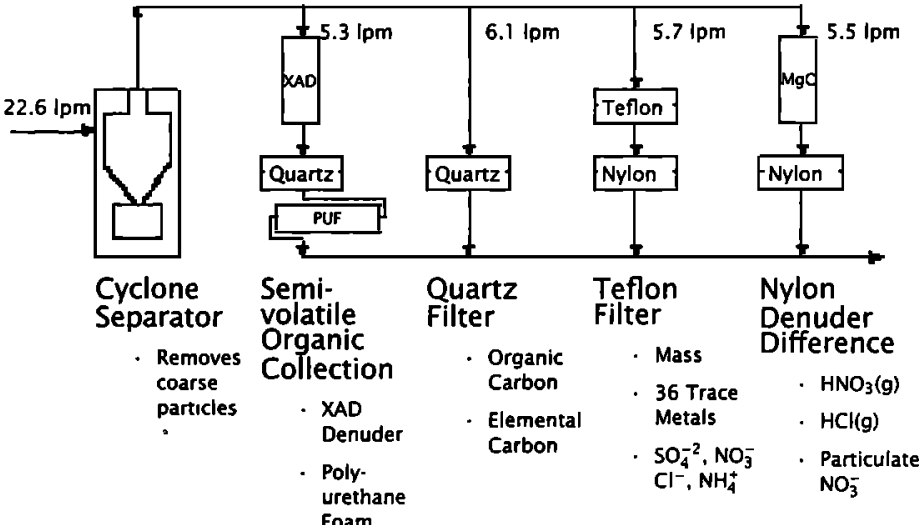

Figure 1. Schematic diagram of sampling equipment used to measure particle size distributions and chemical compositions.

the component chemical substances in the airborne particles were measured at the Maldive Islands in the Indian Ocean during February 1999. The data were taken as part of the 1999 Indian Ocean Experiment (INDOEX) intensive field study conducted at Kaashidhoo in the Maldive Islands and thus are accompanied by extensive supporting measurements of light scattering, light absorption, and aerosol properties taken by other investigators during INDOEX.

\section{Experimental Methods}

During the period of February 11 to 26, 1999, atmospheric particle samples were collected over consecutive 2-day periods at the Kaashidhoo Climate Observatory (KCO) on Kaashidhoo Island $\left(4.96^{\circ} \mathrm{N}, 73.47^{\circ} \mathrm{E}\right)$ in the Republic of Maldives. Two filter samplers and four microorifice uniform deposit impactors (MOUDIs) were operated simultaneously on the roof of the observatory's laboratory building at an elevation of $3 \mathrm{~m}$ above ground level. Filter samplers were used because the comparatively large samples collected place most aerosol parameters readily within tight detection limits. The impactors are seen as the most practical way to measure bulk particle chemical composition as a function of particle size. The sampling equipment is shown schematically in Figure 1. Samples were collected at ambient temperature (typically $27^{\circ}-29^{\circ} \mathrm{C}$ ) and relative humidity (typically $80-89 \% \mathrm{RH}$ ) for 46 hours out of every 48 hours, starting at 1800 local time (LT) every second day. Samples collected on the lower three stages of the impactors are very small, with $\sim 1 \mu \mathrm{g} \mathrm{m}^{-3}$ of particulate matter or less in the size ranges sampled by each of the last three impactor stages. Samples of 2-day duration were taken in order to bring sample sizes on the impactor stages to a level where one standard deviation of the mass determination would be approximately $\pm 0.2 \mu \mathrm{g} \mathrm{m}^{-3}$. This permits very accurate mass determination on the third from last impactor stage at all times and significant mass measurements on the second to last stage much of the time. This increased accuracy of the measurements is of course obtained at the expense of the ability to detect short-term fluctuations in aerosol concentration. Vasiliou et al. [1999] have shown that particle bounce within impactors is effectively suppressed by sampling at $\sim \mathbf{8 0 \%} \mathrm{RH}$. Since the ambient $\mathrm{RH}$ at Kaashidhoo Island was in this range during these experiments, we both size the particles as they actually exist in the atmosphere and in a way that suppresses particle bounce by sampling at ambient RH.

Total suspended particulate matter (no particle size discrimination) and fine particulate matter (aerodynamic diameter $D_{a}<1.8 \mu \mathrm{m}$ ) samples were collected using a Caltechbuilt filter sampling system. In this work we emphasize fine particle characterization because previous research shows that fine particles contribute approximately two thirds of the aerosol optical depth over the Indian Ocean [Satheesh et al., 1999]. The 


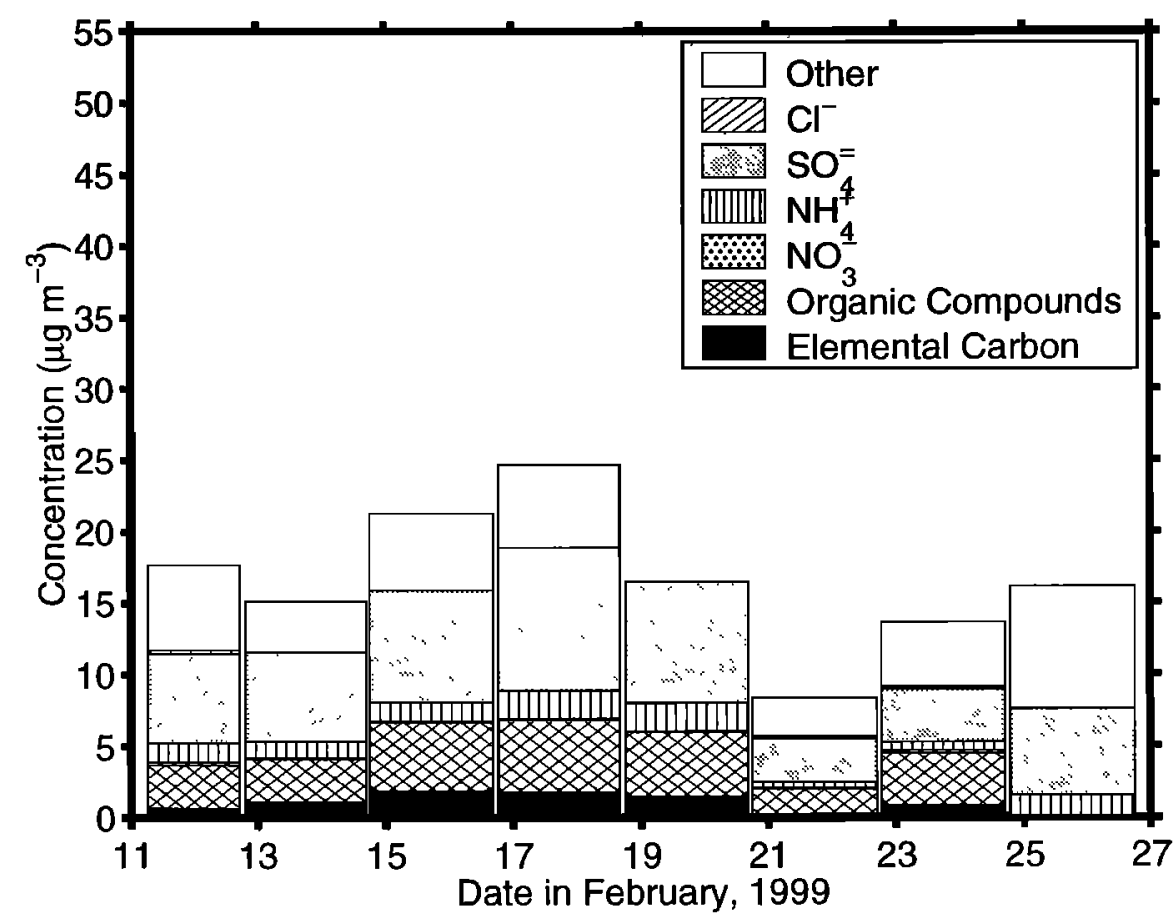

Figure 2. Time series of fine particle $\left(D_{a}<1.8 \mu \mathrm{m}\right)$ mass concentration and chemical composition at Kaashidhoo Island, February 11-26, 1999, based on the Caltech filter sampler.

flow rates for the total and fine particulate matter filter sampling lines are shown in Figure 1. Total suspended particulate matter was collected on one open-face quartz fiber filter (Pallflex, 2500 $\mathrm{QAO}$, 47-mm diameter) and on two parallel open-faced Poly Tetra Fluoro Ethylene (PTFE) filters (Gelman Sciences, Teflo, 47-mm diameter, $1.0-\mu \mathrm{m}$ pore size). Fine particulate matter was collected on one quartz fiber filter (Pallflex, 2500 QAO, 47-mm diameter) and on two PTFE filters (Gelman Sciences, Teflo, 1.0$\mu \mathrm{m}$ pore size). For collection of the fine particles, ambient air was drawn at a rate of $30 \mathrm{lpm}$ through a glass inlet line to a Teflon-coated AIHL-design cyclone separator [John and Reischl, 1980], which removed large particles according to a collection efficiency curve having a $50 \%$ aerodynamic cutoff diameter at $1.8 \mu \mathrm{m}$ before the air passed through the fine particle collection filters. The 15 and $85 \%$ particle collection cut points for this cyclone at this flowrate are at $\sim 1.7-$ and $2.2-\mu \mathrm{m}$ aerodynamic diameter, respectively, based on visual extrapolation of the collection efficiency curves presented by John and Reischl [1980]. The airflow rate through each filter assembly was measured before and after each 46-hour sampling period using a rotameter that had been calibrated against a bubble flow meter; uncertainties in the airflow rate are $\pm 3 \%$ and would affect the cyclone $50 \%$ cutoff diameter by $\pm 0.05 \mu \mathrm{m}$.

Four 10-stage microorifice uniform deposit impactors (MOUDI, MSP Corporation, Model 100) [Marple et al., 1991] were simultaneously operated to measure 46-hour average particulate mass concentration and chemical composition as a function of particle size. To suppress particle bounce from the upper stages of the impactors, ambient air was passed through a Teflon-coated AIHL-design cyclone separator placed upstream of the inlet of each of the four impactors to capture coarse particles $\left(D_{a}>1.8 \mu \mathrm{m}\right)$ [John and Reischl, 1980]. Particles over the size range $0.056-1.8 \mu \mathrm{m}$ particle diameter were collected on impaction stages 5 through 10 of the impactors. All 10 stages of the impactors were in place during the experiment, but only the lower 6 stages collected meaningful samples because of the presence of the cyclone separator upstream of the impactors. Two of the four impactors were loaded with aluminum foil substrates (MSP Corporation, 47-mm diameter) and a quartz fiber afterfilter (Pallflex, $2500 \mathrm{QAO}, 47-\mathrm{mm}$ diameter). The remaining two impactors were operated with PTFE impaction substrates and afterfilters (Gelman Sciences, 47-mm diameter, Teflo material, $1.0-\mu \mathrm{m}$ pore size). Foil impaction substrates and quartz fiber filters were baked before use in order to lower their carbon blank values, since these materials were dedicated to the analysis of carbonaceous aerosol species; foil substrates were baked for 48 hours at $550^{\circ} \mathrm{C}$, and quartz fiber filters were baked for 12 hours at $550^{\circ} \mathrm{C}$. To avoid contamination by organic compounds, no grease or oil was applied to the impaction substrates. Filter samples and samples on impaction substrates were placed in petri dishes, sealed with Teflon tape, then frozen immediately after collection and until subsequent analysis.

All foil and PTFE impaction substrates and PTFE filters were gravimetrically analyzed by repeated weighing before and after the experiment on a Mettler model M-55-A mechanical microbalance maintained in a temperature and humiditycontrolled environment $\left(21.0 \pm 0.2^{\circ} \mathrm{C}, 39 \pm 3 \% \mathrm{RH}\right)$. PTFE impactor substrates were cut in half before chemical analysis to allow the use of several different chemical analysis techniques. One half of the each of the PTFE impactor substrates and one of each pair of PTFE filter samples were analyzed by ion chromatography (Dionex Corporation, Model 2020i) for the anions $\mathrm{NO}_{3}, \mathrm{SO}_{4}^{2-}$, and $\mathrm{Cl}^{-}[$Mulik et al., 1976] and by an indophenol colorimetric procedure for $\mathrm{NH}_{4}^{+}$[Bolleter et al., 1976] using an Alpkem rapid flow analyzer (Model RFA-300). The second half of each of these sample sets is being analyzed for trace elements using neutron activation analysis [Olmez, 1989], and trace elements concentration values will be posted to the INDOEX Web site when they become available.

Foil and quartz fiber substrates were analyzed for elemental and organic carbon content using the thermal-optical carbon analysis method of Huntzicker et al. [1982] as modified by Birch and Cary [1996]. Correction for pyrolytic formation of 
a)

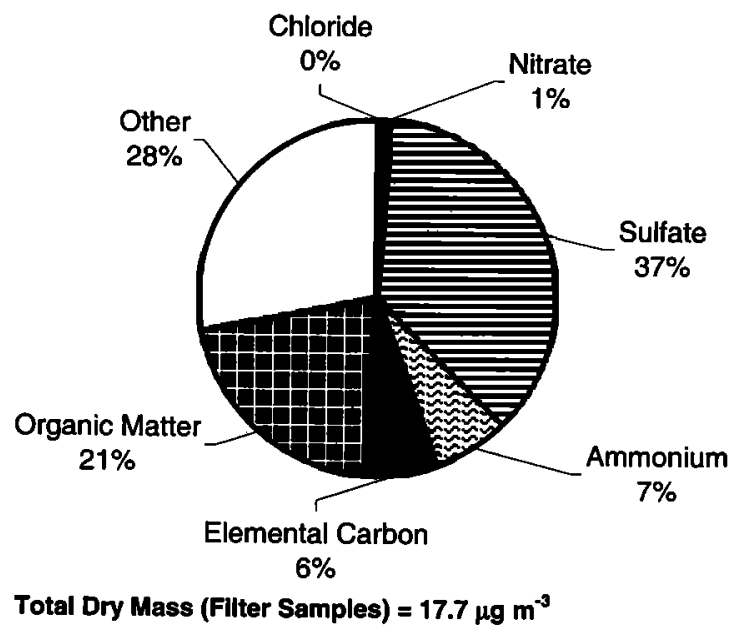

b)

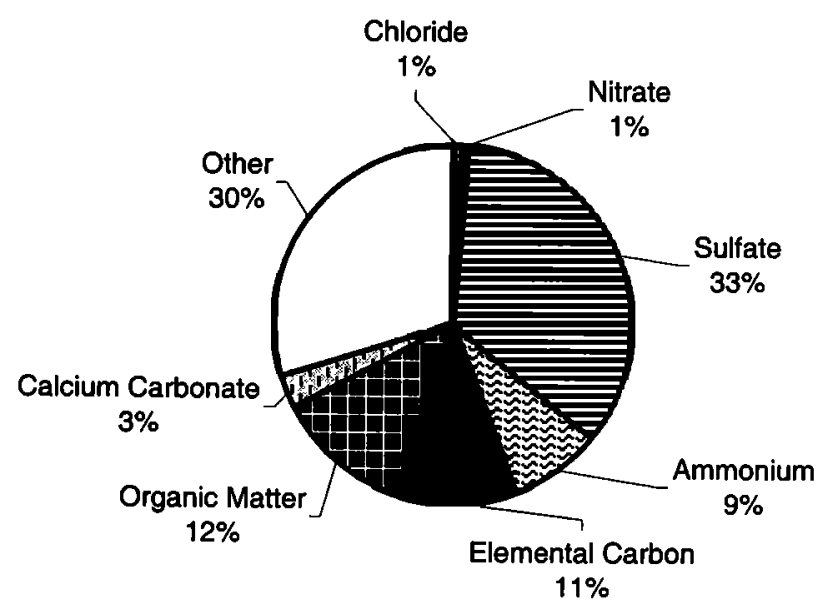

Total Dry Mass (MOUDI) $=17.1 \mu \mathrm{g} \mathrm{m}^{-3}$

Figure 3. Material balance on the average concentration and chemical composition of fine particles $\left(D_{a}<1.8\right.$ $\mu \mathrm{m})$ at Kaashidhoo Island during the entire study period based on (a) the Caltech filter sampler and (b) the integration over all MOUDI impactor stages with $D_{a}<1.8 \mu \mathrm{m}$.

elemental carbon during organic carbon determination from the impactor samples was accomplished using the methodology described in the paper by Kleeman et al. [1999a]. Elemental carbon is a form of impure graphite produced by combustion processes [Cass et al., 1982]. Analytical standards for atmospheric elemental carbon particles do not presently exist, and thus elemental carbon concentrations are defined operationally by the analytical method that is used. In the thermal evolution and combustion method of Birch and Cary [1996], elemental carbon is defined as carbon that resists volatilization up to a temperature of $900^{\circ} \mathrm{C}$ in an inert atmosphere in a manner similar to graphite and also is black. For this reason, we use the terms elemental carbon and black carbon interchangeably but with the realization that it is the measurement method of Birch and Cary [1996] that operationally defines the concentration values reported. Variations in elemental carbon values between alternative methods can arise owing to differences in the way that alternative methods correct for charring of the samples during analysis. In the case of the present samples, comparison of the EC values attained by the method of Birch and Cary [1996] versus values obtained without any pyrolysis correction shows an absolute difference in the EC values of $0.47 \pm 0.61 \mu \mathrm{g} \mathrm{EC}$ per $\mathrm{cm}^{2}$ of filter surface analyzed, corresponding to an average $17 \%$ change in the EC concentrations and a $6 \%$ change in the OC concentrations.

For gravimetric mass determination the average precision of the impactor measurements, calculated from the nominally four replicate impactor samples taken each event, was found to be $\pm 5.3 \%$ for samples greater than or equal to $2.0 \mu \mathrm{g} \mathrm{m}^{-3}$, and $\pm 22.5 \%$ for samples less than $2.0 \mu \mathrm{g} \mathrm{m}^{-3}$ whose values were still significantly greater than zero. For sulfate, ammonium ion, organic matter, and elemental carbon the average precision of the measurements based on repeated analysis of standard solutions was $\pm 2.3, \pm 5.4, \pm 11.1$, and $\pm 5.9 \%$, respectively, for samples greater than or equal to $0.2 \mu \mathrm{g} \mathrm{m}^{-3}$. No nitrate concentrations above $0.2 \mu \mathrm{g} \mathrm{m}^{-3}$ were measured on any single impactor stage. For sulfate, nitrate, ammonium ion, organic matter, and elemental carbon the average precision for samples having significant values smaller than $0.2 \mu \mathrm{g} \mathrm{m}^{-3}$ was $\pm 16.4, \pm 12.4$, $\pm 18.4, \pm 34.9$, and $\pm 12.4 \%$, respectively. 


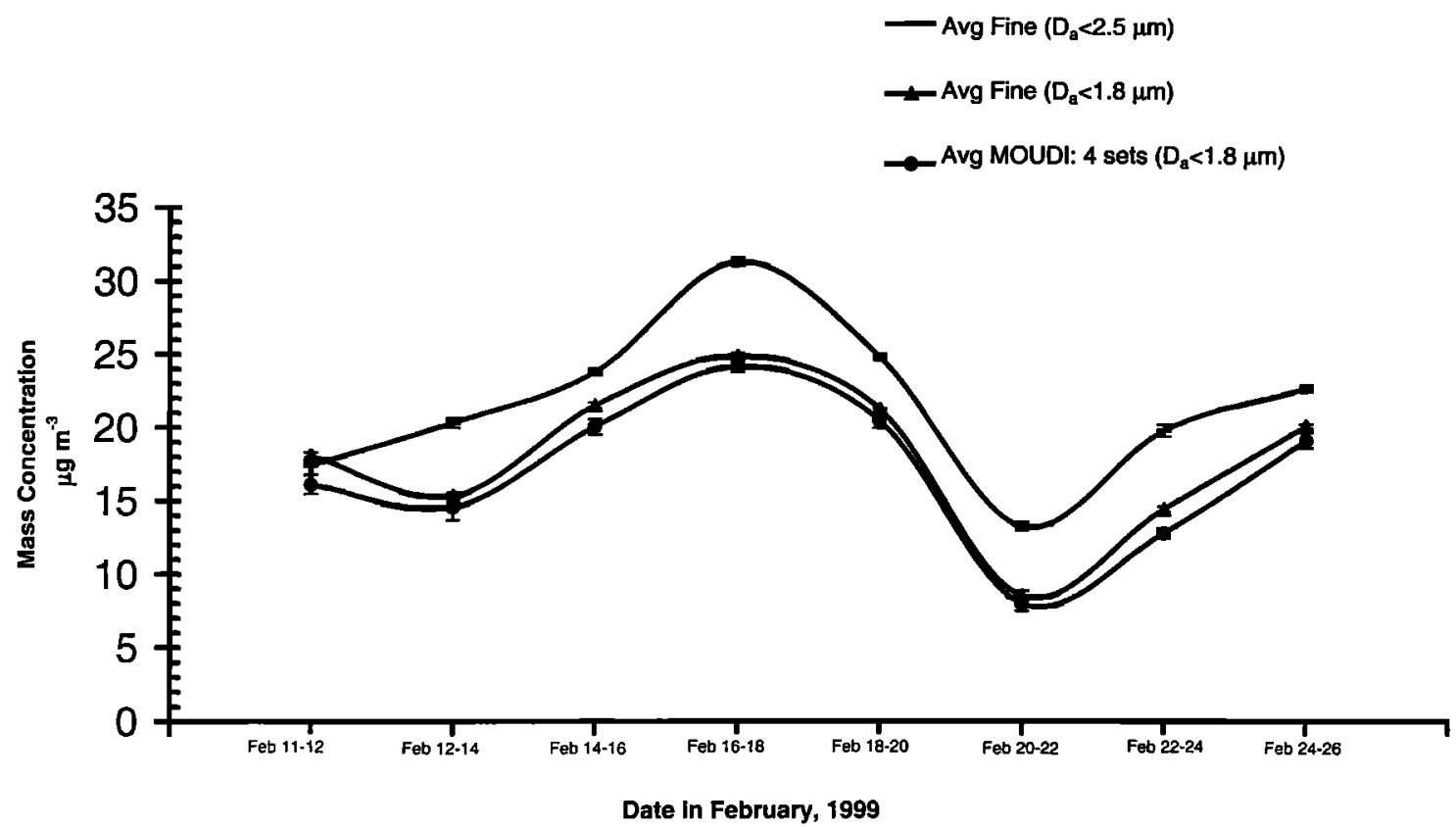

Figure 4. Comparison of the sum of the fine particle mass concentrations measured from impactor stages collecting particles with $D_{a}<1.8 \mu \mathrm{m}$ versus fine particle mass concentrations measured from the Caltech filter sampler $\left(D_{a}<1.8 \mu \mathrm{m}\right)$ and Graseby-Andersen sampler $\left(D_{a}<2.5 \mu \mathrm{m}\right)$.

The uncertainty values just described are based on random errors. There are possible sources of systematic errors that have not been quantified. These include losses in inlets to the samplers (measured by sampling directly from outdoor ambient air into the cyclone inlets), cyclone and impactor size segregation errors minimized by use of the cyclones and high $\mathrm{RH}$ sampling to suppress particle bounce in the impactors, volatilization of aerosol ammonium nitrate (potentially serious if $\mathrm{NH}_{4} \mathrm{NO}_{3}$ is present; see Hering and Cass [1999], positive organic aerosol artifacts due to vapor adsorption or negative organic aerosol artifacts due to volatilization of organics (potentially serious, see McDow [1999]), and uncertainties in the assumed ratio of organic compound mass to organic carbon mass (see Turpin and Lim [2000]; while we assume a value of 1.4 as the ratio of organic compound mass to organic carbon mass, the value calculated from ambient concentration data when the actual organic compounds present are known ranges from 1.2 to 3.0).

In addition to the above instruments, a prototype GrasebyAndersen Sampler (Andersen RAAS, PM 2.5 speciation) was used to collect fine airborne particulate matter in sizes smaller than $2.5-\mu \mathrm{m}$ aerodynamic diameter. Airflow rates and sampling streams for this sampler are shown in Figure 1.

\section{Results and Discussion}

The time series plot in Figure 2 shows the mass concentration and chemical composition of the fine particles $\left(D_{a}<1.8 \mu \mathrm{m}\right)$ based on the Caltech filter sampler results over the entire study period. In these and subsequent mass balance plots, organic compound concentrations are estimated as 1.4 times organic carbon concentrations in order to account for the $\mathrm{H}, \mathrm{O}, \mathrm{S}$, and $\mathrm{N}$ in organic matter [Gray et al.,1986]. The most polluted 46-hour event (fine particle mass concentration $24.7 \pm 0.21 \mu \mathrm{g} \mathrm{m}^{-3}$ ) occurred from February 16 to 18 . This episode was characterized by continental pollution transported from the Indian subcontinent, as explained later in this section. The least polluted 46-hour event (fine particle mass concentration $8.4 \pm 0.33 \mu \mathrm{g} \mathrm{m}^{-3}$ ) occurred from February 20 to 22 . Whenever uncertainties are presented throughout this paper, they reflect $\pm 1 \sigma$ confidence intervals for the individual samples when a single sample is described or $\pm 1 \sigma$ confidence intervals for the mean if the mean of a group of samples is described; these values are determined through analysis of replicate measurements. Because of rain on February 21 and 22, wet deposition of particles probably removed most of the atmospheric pollution. Moreover, backward trajectories indicate that the air parcels sampled at $\mathrm{KCO}$ during February 20-22 originated from the comparatively less polluted environment off the coast of Thailand. As seen in Figure 2, the major fine particle chemical components are $\mathrm{SO}_{4}^{-2}, \mathrm{NH}_{4}{ }^{+}$, organic compounds, and elemental (black) carbon. The sulfate aerosol cannot be present entirely as ammonium sulfate as there are less than 2 moles of $\mathrm{NH}_{4}^{+}$for every mole of $\mathrm{SO}_{4}^{-2}$ in the aerosol.

A material balance on the average concentration of the fine particle $\left(D_{a}<1.8 \mu \mathrm{m}\right)$ chemical species measured by filter-based sampling throughout the entire study period is shown in Figure 3a. Over this measurement period, fine particle mass concentrations averaged $17.7 \pm 0.22 \mu \mathrm{g} \mathrm{m}^{-3} ; 37 \%$ of the mass is sulfate, $7 \%$ is ammonium ion, and $27 \%$ consists of organic compounds plus elemental carbon. The chemical identity of $5.8 \pm 0.4 \mu \mathrm{g} \mathrm{m}^{-3}(28 \%)$ of the fine particle material remains unknown; this residual material is expected to consist of the oxides of crustal trace elements (e.g., $\mathrm{Al}, \mathrm{Fe}$, and $\mathrm{Si}$ ) plus sea salt and some water that remains in the samples despite the fact that they were weighed at $39 \%$ RH. A small amount of the crustal material is found in nearly all of the fine particle samples that we have taken elsewhere [e.g., Christoforou et al., 1999; Gray et al., 1986; Salmon et al., 1999], while sea salt is expected given the coastal location at Kaashidhoo Island. Total suspended particulate matter (TSP) concentrations averaged 10 times higher than fine particle concentrations over the four sampling events where TSP data are available; we do not have enough chemical information on the composition of the coarse particles to warrant further discussion.

The sum of the masses collected on impactor stages 5 to 10 provides an additional measure of overall fine particle mass 

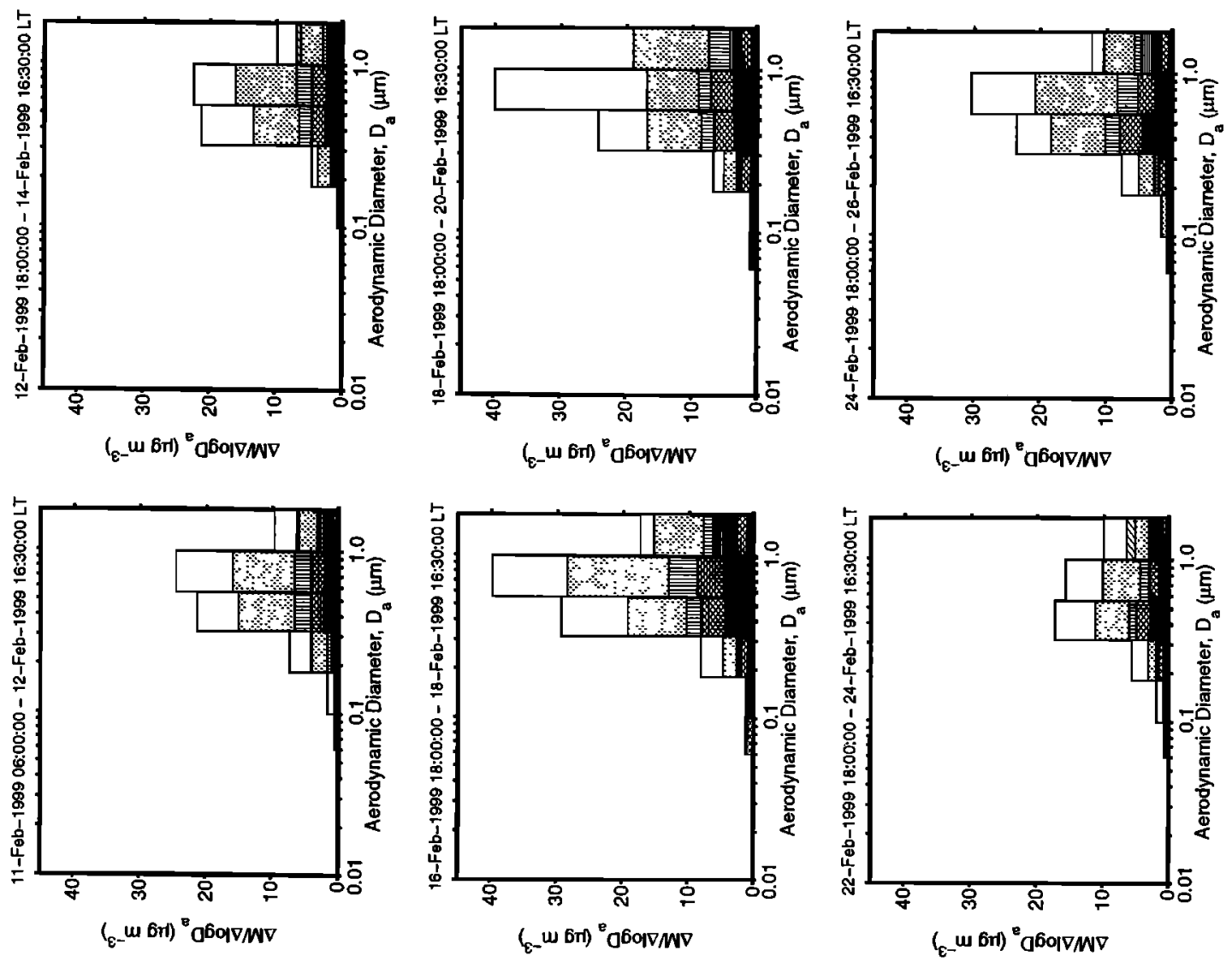

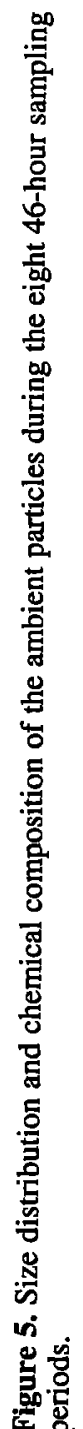
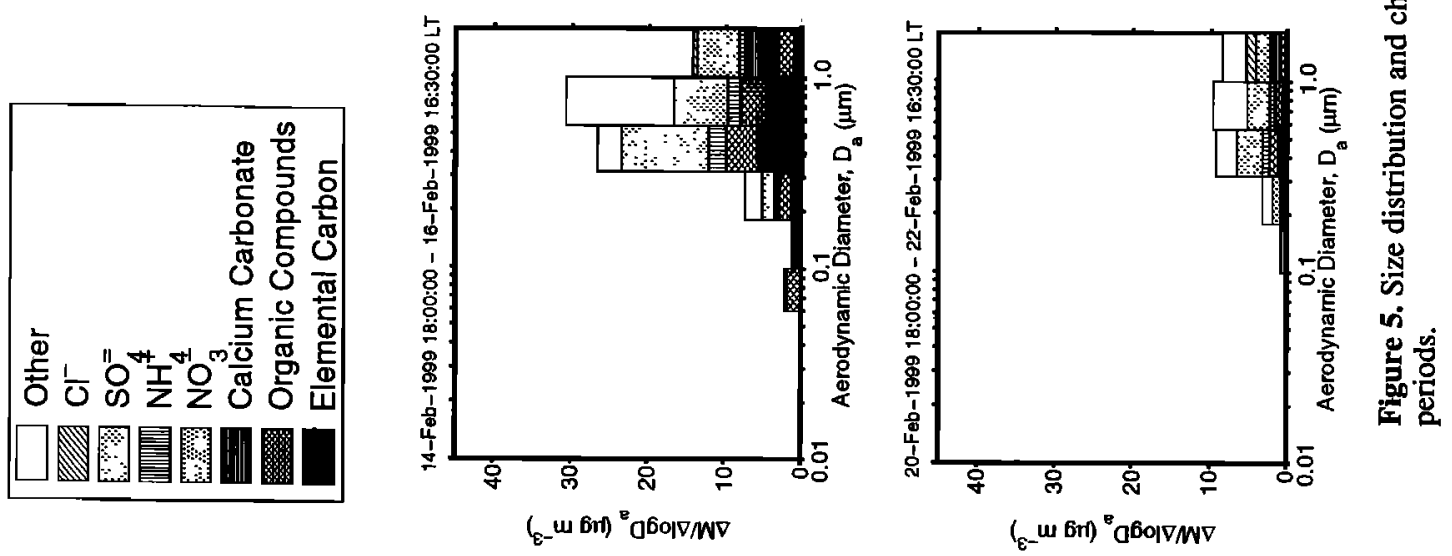
a)

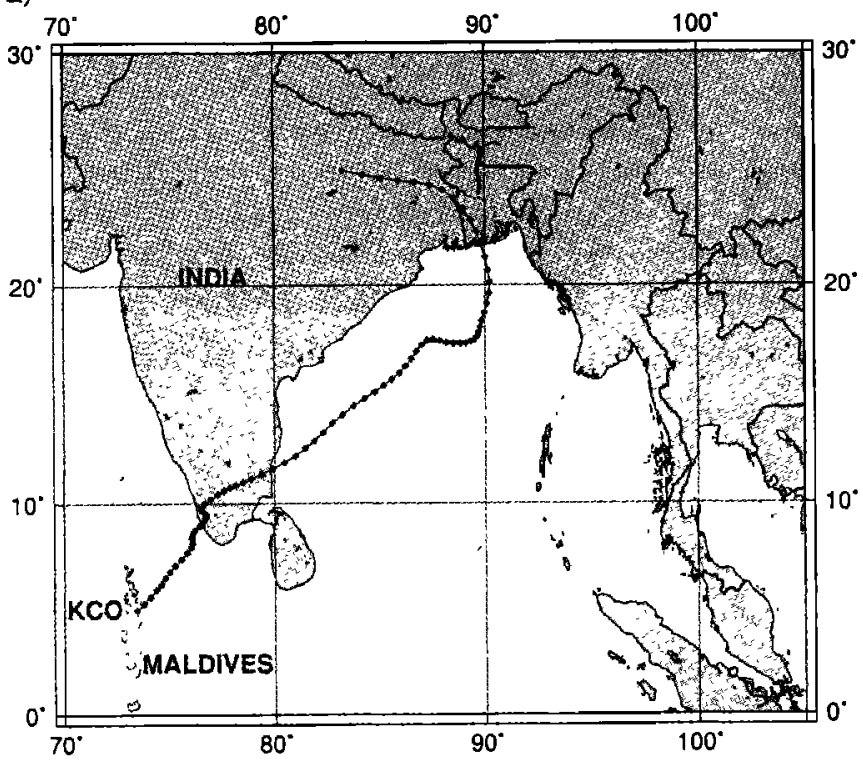

b)

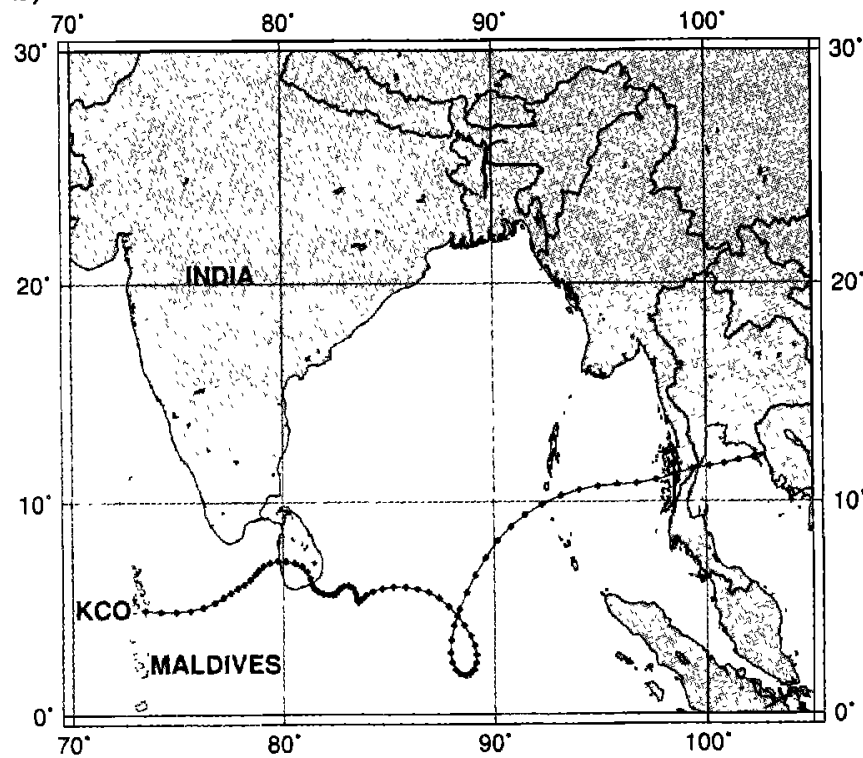

Figure 6. Typical 10-day backward trajectory for air parcels arriving at Kaashidhoo Island at 0600 local time (a) on February 16 during a high pollution event and arriving at 0600 local time (b) on February 22 during a low pollution event.

concentration $\left(D_{a}<1.8 \mu \mathrm{m}\right)$ that can be compared to the sub-1.8 $\mu \mathrm{m}$ and sub-2.5 $\mu \mathrm{m}$ fine particle mass concentrations measured by the Caltech filter sampler and Graseby-Andersen filter sampler, respectively. The sub-1.8 $\mu \mathrm{m}$ particle mass concentrations measured by the impactors and Caltech filter sampler match very closely throughout the entire study period, as shown in the lower 2 curves in Figure 4, indicating consistency in measurement and in sample analysis.

A material balance on the chemical composition of the impactor samples integrated over all particle sizes $D_{a}<1.8 \mu \mathrm{m}$ is presented in Figure $3 \mathrm{~b}$ for comparison to the sub-1.8 $\mu \mathrm{m}$ diameter particles measured from the filter-based samples. The results of these independent measurements are very close for fine particle mass concentration and for $\mathrm{Cl}^{-}, \mathrm{NO}_{3}{ }^{-}, \mathrm{SO}_{4}^{-2}, \mathrm{NH}_{4}{ }^{+}$, and total carbon. The principal difference seen is in the speciation of the aerosol carbon. The impactor samples suggest that some of the "organic carbon" measured on the quartz fiber filters is actually carbonate carbon that is seen on the largest stage of the impactor samples; a possible source is the coral material from which Kaashidhoo Island is formed. The EC/OC split determined from the impactor samples is more heavily weighted toward elemental carbon. The fine particle mass concentrations as measured by the Graseby-Andersen filter sampler $\left(D_{a}<2.5\right.$ $\mu \mathrm{m})$ exceed the concentrations obtained from the sub- $1.8 \mu \mathrm{m}$ aerodynamic diameter samplers, as expected (see Figure 4).

The size distribution of the chemical components of the atmospheric particle mixture at KCO is shown in Figure 5 based on the impactor data. The particle size distribution is largely unimodal in the submicron particle size range. The peak in the particle mass distribution typically occurs in the $0.56-1.0 \mu \mathrm{m}$ aerodynamic diameter size range, which corresponds approximately to the size range of $0.44-0.79 \mu \mathrm{m}$ particle physical diameter. The density used was $1.55 \mathrm{~g} \mathrm{~cm}^{-3}$. This value was calculated by first forming model compounds from the measured aerosol species as described by Larson et al. [1988], then averaging the densities of those materials followed by estimation of the amount of water present at the sampled RH [Larson et al., 1988; Eldering et al., 1994]. The relative humidities at $\mathrm{KCO}$ averaged (range given in brackets) $81(76$ $83) \%, 82(77-86) \%, 83(77-87) \%, 85(78-87) \%, 84.5(75-92) \%$, $87(82-97) \%, 86.5(84-92) \%$, and $84(78-87) \%$ over the eight consecutive sampling periods shown in Figure 5, respectively.

The size distributions of $\mathrm{SO}_{4}^{-2}$ and $\mathrm{NH}_{4}^{+}$ions follow each other closely, indicating that some $\left(\mathrm{NH}_{4}\right)_{2} \mathrm{SO}_{4}$ and/or $\mathrm{NH}_{4} \mathrm{HSO}_{4}$ probably are present in the fine particles. $\mathrm{Cl}^{-}$and $\mathrm{NO}_{3}{ }^{-}$are found in relatively small amounts, principally in the $1.0-1.8 \mu \mathrm{m}$ aerodynamic diameter range. The chloride indicates the presence of sea salt and the nitrate in particle sizes $>1 \mu \mathrm{m}$ indicates that a small amount of sea-salt has been in some cases partly transformed by atmospheric chemical reactions to produce sodium nitrate. Since chloride can be displaced from the aerosol by reaction with sulfuric or nitric acid, chloride concentrations alone do not permit an accurate assessment of the amount of sea salt present. Given the large amounts of sulfate in the largest impactor size bin, there may be a considerable amount of sodium sulfate present. Once the sodium concentrations become available from neutron activation analysis, they will be posted to the INDOEX Web site and will provide a basis for estimation of sea-salt concentrations subject to the uncertainties of the sodium measurements.

Organic carbon and elemental (black) carbon are most abundant in the size range between $0.32-$ and $1.0-\mu \mathrm{m}$ aerodynamic diameter; this size range extends to larger particle sizes than the $0.1-0.3 \mu \mathrm{m}$ diameter peak characteristic of black carbon from diesel engines in the United States [Kleeman et al., 1999]. Black carbon from coal or biomass burning might be responsible for this pattern; at present the size distribution of elemental carbon from small-scale coal combustion and Indian subcontinent biomass burning is unknown. Alternatively, small primary black carbon-containing particles may become larger through accumulation of secondary aerosol species (e.g., sulfates, secondary organics) over time during multiday transport across India and the Indian Ocean. The other mass values shown in Figures 2, 3, and 5 are believed to consist largely of mineral matter and sea-salt, plus water that is retained in the samples despite the fact that they were weighed at $39 \% \mathrm{RH}$. The mineral matter concentrations can be more thoroughly explored once trace element data become available from neutron activation analysis.

During the northeast monsoon the aerosol concentrations measured at $\mathrm{KCO}$ were much higher than one would expect at a remote island location. Fine particle mass concentrations in 
particles smaller than $1.8-\mu \mathrm{m}$ aerodynamic diameter reached $24.7 \pm 0.21 \mu \mathrm{g} \mathrm{m}^{-3}$ over one 2-day period and averaged 17.7 10.22 $\mu \mathrm{g} \mathrm{m}^{-3}$ over the entire 16 days of this study. By comparison, fine particle concentrations in center of the city of Los Angeles averaged $27.4 \mu \mathrm{g} \mathrm{m}^{-3}$ during 1993 , while such concentrations at San Nicolas Island, upwind and offshore of Los Angeles, averaged $7.7 \mu \mathrm{g} \mathrm{m}^{-3}$ [Christoforou et al., 2000]. Fine particle concentrations averaged $16.2 \mu \mathrm{g} \mathrm{m}^{-3}$ at Kenmore square in Boston in 1995 [Salmon et al., 1999].

Meteorological data link these high aerosol concentrations at KCO during the February 11-26, 1999, period to transport from the Indian subcontinent. Figures $6 \mathrm{a}$ and $6 \mathrm{~b}$ show characteristic 10-day backward trajectories arriving at KCO during the study period for high pollution events and low pollution events, respectively (methodology described by Harris and Kahl [1994]). During high pollution events the air masses originated in Bangladesh, West Bengal, and the northern part of India and accumulated pollutants as they passed down the eastern coast and southern tip of India before reaching $\mathrm{KCO}$. Although coarse particles larger than several microns in diameter may settle from the atmosphere via dry deposition, there is a strong possibility that smaller fine aerosols from India and Bangladesh will be transported to the area of the Indian ocean near $\mathrm{KCO}$ without experiencing wet or dry removal. During February 20-22 a different wind trajectory was observed, accompanied by lower levels of pollution (see Figure $6 \mathrm{~b}$ ). That air mass originated from southern Thailand and crossed the Bay of Bengal before reaching $\mathrm{KCO}$. During passage of this air mass, rain occurred thus removing particles by wet deposition.

The Indian Ocean aerosol during the winter monsoon contains a mixture of aerosol components at concentrations typical of urban pollution levels in the United States and with a surprisingly large amount of black carbon that can be expected to lead to high levels of light absorption. The size distribution and chemical composition data from our cascade impactors is sufficient to support a theoretical analysis of the causes of light scattering and light absorption over the Indian Ocean based on Mie theory scattering and absorption calculations [Eldering and Cass, 1996]. That analysis could be used to directly link the extent of climate forcing by aerosols over the Indian Ocean to the aerosol size distribution and chemical composition. Ultimately, particle size and chemical composition data will permit tests of models that connect source emissions to climate forcing by aerosols.

Acknowledgments. This work was supported by the University Corporation for Atmospheric Research (UCAR) and by the Caltech Center for Air Quality Analysis.

\section{References}

Andreae, M. O., Future Climates of the World, edited by A. HendersonSellers, Elsevier, New York, 1995.

Birch, M. E., and R. A. Cary, Elemental carbon-based method for monitoring occupational exposures to particulate diesel exhaust, Aerosol Sci. Technol., 25, 221-241, 1996.

Bolleter, W.T., C. T. Bushman, and P. W. Tidwell, Spectrophotometric determinations of ammonium as indophenol, Anal. Chem., 33, 592$594,1961$.

Cass. G. R., P. M. Boone, and E. S. Macias, Emissions and air quality relationships for atmospheric carbon particles in Los Angeles, in Particulate Carbon: Atmospheric Life Cycle, edited by G. T. Wolff and R. L. Klimisch, pp. 207-240, Plenum, New York, 1982.

Charlson, R. J., J. Langner, and $H$. Rodhe, Sulfate aerosol and climate, Nature, 348, 22-22, 1990.

Charlson, R. J., J. Langner, H. Rodhe, C. B. Levoy, and S. G. Warren, Perturbation of the northern-hemisphere radiative balance by backscattering from anthropogenic sulfate aerosols, Tellus, Ser. A, 43, 152-163, 1991 .
Charlson, R. J., S. E. Schwartz, J. M. Hales, R. D. Cess, J. A. Coakley, J. E. Hansen, and D. J. Hofman, Climate forcing by anthropogenic aerosols, Science, 255, 423-430, 1992

Christoforou, C. S., L. G. Salmon, and G. R. Cass, Passive filtration of airborne particles from buildings ventilated by natural convection: Design procedures and a case study at the Buddhist Cave Temples at Yungang, China, Aerosol Sci. and Technol., 30, 530-544, 1999.

Christoforou, C. S., L. G. Salmon, M. P. Hannigan, P. A. Solomon, and G. R. Cass, Trends in fine particle concentration and chemical composition in Southern California, J. Air Waste Manag. Assoc., 50, 43-53, 2000.

Eldering, A., and G. R. Cass, Source-oriented model for air pollutant effects on visibility, J. Geophys. Res., 101, 19,343-19,369, 1996.

Eldering, A., G. R. Cass, and K. C. Moon, An air monitoring network using continuous particle size distribution monitors connecting pollutant properties to visibility via Mie scattering calculations, Atmos. Environ., 28, 2733-2749, 1994.

Gray, H. A., G. R. Cass, J. J. Huntzicker, E. K. Heyerdahl, and J. A. Rau, Characteristics of atmospheric organic and elemental carbon particle concentrations in Los Angeles, Environ. Sci. Technol., 20, $580-589,1986$.

Harris, J. M., and J. D. W. Kahl, Analysis of 10-day isentropic flow patterns for Barrow, Alaska-1985-1992, J. Geophys. Res., 99. 25,845-25,855, 1994.

Hering, S., and G. Cass, The magnitude of bias in the measurement of PM2.5 arising from volatilization of particulate nitrate from teflon filters, Air Waste Manag. Assoc., 49, 725-733, 1999.

Huntzicker, J. J., R. L. Johnson, J. J. Shah, and R. A. Cary, Particulate Carbon. Atmospheric Life Cycle, edited by G. T. Wolff and R. L. Klimisch, pp. 79-88, Plenum, New York, 1982.

John, W., and G. Reischl, A cyclone for size-selective sampling of ambient air, J. Air Pollut. Control Assoc., 30, 872-876, 1980.

Kiehl, J. T., Clouds and their effects on the climate system, Phys. Today, 47, 36-42, 1994.

Kiehl, J. T., and B. P. Briegleb, The relative roles of sulfate aerosols and greenhouse gases in climate forcing, Science, 260, 311-314, 1993.

Kleeman, M. J., J. J. Schauer, and G. R. Cass, Size and composition distribution of fine particulate matter emitted from wood burning, meat charbroiling, and cigarettes, Environ. Sci. Technol., 33, 3516$3523,1999$.

Kleeman, M. J., L. S. Hughes, J. O. Allen, and G. R. Cass, Source contributions to the size and composition distribution of atmospheric particles: Southem California in September 1996, Environ. Sci. Technol., 33, 4331-4341, 1999.

Krishnamurti, T. N., B. Jha, J. Prospero, A. Jayaraman, and V. Ramanathan, Aerosol and pollutant transport and their impact on radiative forcing over the tropical Indian Ocean during the JanuaryFebruary 1996 pre-INDOEX cruise, Tellus, Ser. B, 50, 521-542, 1998.

Larson, S. M., G. R. Cass, K. J. Hussey, and F. Luce, Verification of image processing based visibility models, Environ. Sci. Technol., 22, 629-637, 1988

Larson, S. M., G. R. Cass, and H. A. Gray, Atmospheric carbon particles and the Los Angeles visibility problem, Aerosol Sci. Technol., 10, 118-130, 1989.

Marple, V. A., K. L. Rubow, and S. M. Behm, A microorifice uniform deposit impactor (MOUDI), description, calibration, and use, Aerosol Sci. Technol., 14, 434-446, 1991.

McDow S. R., Sampling artifact errors in gas/particle partitioning measurements, in Gas and Particle Phase Measurements of Atmospheric Organic Compounds, edited by Douglas A. Lane, pp. 105-126, Gordon and Breach Sci., Newark, N.J., 1999.

Mulik, J., R. Puckett, D. Williams, and E. Sawicki, Ion chromatographic analysis of sulfate and nitrate in ambient aerosols, Anal. Lett., 9, 653-663, 1976.

Olmez, I., in Methods of Air Sampling Analysis, 3rd ed., edited by J. P. Lodge, pp. 143-150, Lewis, Chelsea, Mich., 1989.

Prospero, J. M., Mineral and sea salt aerosol concentrations in various ocean regions, J. Geophys. Res., 84, 725-31, 1979.

Salmon, L. S., G. R. Cass, D. U. Pedersen, J. L. Durant, R. Gibb, A. Lunts, and $M$. Utell, Determination of fine particle and coarse particle concentration and chemical composition in the northeastem United States, 1995, report, Northeast States for Coordinated Air Use Management (NESCAUM), Boston, Mass., 1999.

Satheesh, S. K., V. Ramananathan, X. Li-Jones, J. M. Lobert, I. A. Podgomy, J. M. Prospero, B. N. Holben, and N. G. Loeb, A model for the natural and anthropogenic aerosols over the tropical Indian Ocean derived from Indian Ocean Experiment data, J. Geophys. Re.,, 104, 27, 421-40, 1999. 
Taylor, K. E., and J. E. Penner, Response of the climate system to atmospheric aerosols and greenhouse gases, Nature, 369, 734-737, 1994.

Turpin, B. J., and H. J. Lim, Species contributions to PM2.5 mass concentrations: Revisiting common assumptions for estimating organic mass, Aerosol Sci. Technol., in press, 2001.

Vasiliou, J. G., D. Sorensen, and P. H. McMurry, Sampling at controlled relative humidity with a cascade impactor, Atmos. Environ., 33, 1049-1056, 1999.

Wigley, T. M. L., Possible climate change due to $\mathrm{SO}_{2}$-derived cloud condensation nuclei, Nature, 339, 365-367, 1989.

Zhang, X. Q., P. H. McMurry, S. V. Hering, and G. S. Casuccio, Mixing characteristics and water-content of submicron aerosols measured in Los Angeles and at the Grand Canyon, Atmos. Environ. 27A, 1593-1607, 1993.
G. R. Cass, School of Earth and Atmospheric Sciences, Georgia Institute of Technology, Atlanta, GA 30332-0340.

Z. Chowdhury, L. S. Hughes, and L. G. Salmon, Environmental Engineering and Science Department, MC 138-78, California Institute of Technology, Pasadena, CA 91125. (zohir@caltech.edu lara@caltech.edu; salmon@eql14.caltech.edu)

(Received June 28, 2000; revised December 18, 2000; accepted December 19,2000.) 